\title{
Genotype by Environment Interaction for Production Traits While Accounting for Heteroscedasticity
}

\author{
A. G. Fahey, ${ }^{1}$ M. M. Schutz, D. L. Lofgren, A. P. Schinckel, and T. S. Stewart \\ Department of Animal Sciences, Purdue University, West Lafayette, IN 47907
}

\begin{abstract}
Grazing $(G)$ provides an alternative management system for dairy production. Heteroscedasticity (HV) of the data may bias estimates of genetic correlations of yield traits between environments, an indicator of genotypeby-environment interaction $(\mathrm{G} \times \mathrm{E})$. The objective of this study was to investigate the effect of HV on estimates of heritabilities and genetic correlations for matureequivalent milk, protein, and fat yield, and lactationaverage somatic cell scores of daughters, and to determine if $\mathrm{HV}$ affects the ability of sire's predicted transmitting ability (PTA) to predict daughter production in $\mathrm{G}$ and confinement (C) herds. Data consisted of 72,489 records from 35,674 cows in $366 \mathrm{G}$ herds from 11 states, and 117,629 records from 50,963 cows in $373 \mathrm{C}$ herds from the same 11 states plus 1 geographically contiguous state. Herds were divided into variance quartiles $\left(\mathrm{Q}_{\mathrm{V}} 1-\mathrm{Q}_{\mathrm{V}} 4\right)$ based on milk yield. A transformation was used to reduce HV by standardizing the within-herd standard deviation to the average across-herd standard deviation of a base year for each parity, and was similar to the method used in current USDA-DHIA genetic evaluations. Regression of daughter yield on sire PTA showed that PTA overestimated production of all traits in $\mathrm{Q}_{\mathrm{V}} 1-\mathrm{Q}_{\mathrm{V}} 3$ and of milk in $\mathrm{Q}_{\mathrm{V}} 4$ of $\mathrm{G}$ herds. For $\mathrm{C}$ herds, yields of milk in $Q_{\mathrm{V}} 1$ and $\mathrm{Q}_{\mathrm{V}} 2$, and of protein and fat in $Q_{V} 1$ were overestimated, and protein was underestimated in $\mathrm{Q}_{\mathrm{V}} 4$. Reducing $\mathrm{HV}$ had little effect on $\mathrm{G}$ herds, but for $\mathrm{C}$ herds, regression did not differ from unity for milk and protein in $\mathrm{Q}_{\mathrm{V}} 1$ and $\mathrm{Q}_{\mathrm{V}} 2$. For milk, protein, and fat in G, heritabilities were approximately 0.17 , 0.17 , and 0.19 , respectively. The heritabilities for milk, protein, and fat in C herds were approximately 0.16 , 0.17 , and 0.21 , respectively. Genetic correlations between $\mathrm{C}$ and $\mathrm{G}$ did not suggest a $\mathrm{G} \times \mathrm{E}$ in 3 upper quartiles, but a possible $\mathrm{G} \times \mathrm{E}$ (correlation $=0.21$, estimated standard error $=0.22$ ) for the lowest quartile. Reducing HV did not affect estimates of heritabilities
\end{abstract}

Received October 24, 2006.

Accepted April 27, 2007.

${ }^{1}$ Corresponding author: agfahey@purdue.edu or genetic correlations. Results indicated that modest evidence for existence of $\mathrm{G} \times \mathrm{E}$ did not arise solely from HV.

Key words: heteroscedasticity, heritability, variance quartile

\section{INTRODUCTION}

National genetic evaluations of dairy sires in the United States use the BLUP method to calculate PTA of sires. The BLUP method assumes homoscedasticity; however, with production data this is rarely the case. For most biological traits, variance is a function of the mean: as the mean increases, so does the variance (Dette and Wong, 1999).

Calus et al. (2002) suggested that grouping herds by production system or intensity of production and then determining if genotype-by-environment interaction $(\mathbf{G} \times \mathbf{E})$ was present might be useful. A $\mathrm{G} \times \mathrm{E}$ occurs when sires' ranking for a trait changes between 2 environments. A scaling effect occurs when the rank of sires in 2 environments is the same, but the production level of their progeny in one environment is lower than in the other environment. Previous work on mature-equivalent milk (MEM), protein (MEP), and fat (MEF) by Kearney et al. (2004a) did not find evidence of a large $\mathrm{G} \times \mathrm{E}$ between grazing $(\mathbf{G})$ and confinement $(\mathbf{C})$ herds. In that study, genetic correlations between both management systems for MEM, MEP, and MEF were found to be $0.89,0.91$, and 0.88 , respectively. A study to determine if a $\mathrm{G} \times \mathrm{E}$ was present for lactation-average SCS (LSCS) did not show that a $\mathrm{G} \times \mathrm{E}$ existed between $\mathrm{G}$ herds and $\mathrm{C}$ herds with a genetic correlation of 0.89 (Kearney et al., 2004b). In those studies, heteroscedasticity was considered in selected methodology.

Heteroscedasticity exists for both production and conformation traits (Boldman and Freeman, 1990; Smothers et al., 1991, 1993; Van der Werf et al., 1994). Ignoring heteroscedasticity may cause a bias in genetic evaluations (Vinson, 1987; Van der Werf et al., 1994), and the bias may become more severe as selection intensity increases (Vinson, 1987). Van der Werf et al. (1994) suggested that EBV for sires are biased, because dams of sires are high producers, and therefore the variability 
of their production records is greater, leading to a bias in calculations. Hill (1984) suggested that ignoring heteroscedasticity could lead to selecting animals from more-variable herds, resulting in a decrease in response to selection that would be detrimental to long-term genetic improvement. Accounting for heteroscedasticity improves the accuracy of evaluations. However, some research has shown that transformation for heteroscedasticity had only a small effect on rankings of animals (Winkleman and Schaeffer, 1988; Sullivan and Schaeffer, 1989; Wiggans and VanRaden, 1991). Other studies have shown that a moderate reranking of animals occurs when heteroscedasticity is taken into account (Meinert et al., 1988; Boldman and Freeman, 1990).

Various methods have been used to reduce the effect of heteroscedasticity. A log transformation was used in the northeastern United States (Everett and Keown, 1984). Further analysis of this approach showed that with a log transformation, herds with lowest yields had the greatest number of elite cows (Mirande and Van Vleck, 1985; Short et al., 1990), suggesting an overcompensation for heterogeneity of variance. A Bayesian approach was adopted in Australia. This method regressed herd variance toward a population variance; however, a constant heritability was assumed throughout the population (Jones and Goddard, 1990). Heteroscedasticity was adjusted as a weighted mean for herdyear-region, variation in adjacent years for the same herd-parity, and region-year-parity variance in a study reported by Wiggans and VanRaden in (1991), and this method is currently used in the United States.

The first objective of this study was to determine if accounting for heteroscedasticity by using a method similar to that used by the USDA in the US national genetic evaluations affected the ability of sires' PTA to predict daughter production of MEM, MEP, MEF, and LSCS in G and C herds. The second objective was to determine if accounting for heteroscedasticity affected the heritabilities of the 4 traits and to ascertain whether heteroscedasticity produced sufficient extraneous variance to mask the underlying scaling effects or $\mathrm{G} \times \mathrm{E}$. The hypothesis for this study was that standardization of within-herd standard deviation would reduce extraneous variance sufficiently to unmask scaling effects and $\mathrm{G} \times \mathrm{E}$ for milk, fat, protein, and LSCS between the G and $\mathrm{C}$ environments.

\section{MATERIALS AND METHODS}

Grazing herds were defined as herds in which cows used pasture as a source for the majority of their forage consumption for at least 6 mo of the year. All herds used in this study were identified with the help of grazing
Table 1. Number of states, herds, records, cows and sires used in the analysis for mature-equivalent milk (MEM), protein (MEP), fat (MEF), and lactation-average somatic cell score (LSCS)

\begin{tabular}{|c|c|c|c|c|}
\hline \multirow[b]{3}{*}{ Variable } & \multicolumn{4}{|c|}{ Group } \\
\hline & \multicolumn{2}{|c|}{ MEM, MEP, MEF } & \multicolumn{2}{|c|}{ LSCS } \\
\hline & Grazing & Confinement & Grazing & Confinement \\
\hline States & 11 & 12 & 11 & 12 \\
\hline Herds & 366 & 373 & 366 & 373 \\
\hline Records & 72,489 & 117,629 & 68,165 & 108,151 \\
\hline Cows & 35,674 & 50,963 & 28,635 & 45,486 \\
\hline Sires & 4,048 & 6,268 & 3,638 & 5,900 \\
\hline
\end{tabular}

consultants, grazing specialists, and DHI personnel, and were enrolled in the DHI recording program. Contemporary DHI herds of similar size that were not known to be utilizing grazing (as defined above) were selected as $\mathrm{C}$ herds. In some states, few $\mathrm{C}$ herds were available, so $\mathrm{C}$ herds from other states were used to obtain a similar number of herds in the region. Herds were split into 2 management systems. Data were provided by Dairy Records Management Services (Raleigh, NC).

Analysis of MEM, MEP, MEF, and LSCS utilized data from $366 \mathrm{G}$ herds in 11 states (New York, Indiana, Michigan, Iowa, Kansas, Virginia, North Carolina, South Carolina, Mississippi, Louisiana, and Oklahoma) consisting of 72,489 records from 35,674 cows with 4,048 sires. Confinement data consisted of 117,629 records of 50,963 cows with 6,268 sires in 373 herds in 12 states (same 11 states plus Illinois) as shown in Table 1. The LSCS records were from $366 \mathrm{G}$ herds from 11 states with 68,165 records from 28,635 cows with 3,638 sires, and $373 \mathrm{C}$ herds from 12 states with 108,151 records from 45,486 cows with 5,900 sires (Table 1 ). There were 3,408 sires common to both the $\mathrm{G}$ and $\mathrm{C}$ herds. Seven edits were applied to the data set. The first 6 are as suggested by Kearney et al. (2004a): 1) only records after 1990 were included in the analysis; 2) cows must have at least 1 lactation; 3) sire and dam pedigree information was required for all cows; 4) sixth and later lactations were deleted from the data set; 5) records more than 4 standard deviations from the mean of MEM, MEP, MEF, and LSCS were removed from analysis; and 6) lactations must have been at least 60 $d$ long. In addition, cows with age of calving of less than 17 mo and greater than 135 mo for lactations 1 through 5 were deleted. Pedigree information for this study was supplied by the USDA Animal Improvement Programs Laboratory (Beltsville, MD). Kearney et al. (2004a) carried out analyses on quartiles based on mean MEM; however, in the current study we are investigating the effect of heteroscedasticity on production data based on variance (MEM) quartiles. Our data set was similar to 
Table 2. Characteristics of populations of cows and sires in grazing and confinement herds and animals used in the relationship matrices by variance quartiles based on mature-equivalent milk yield

\begin{tabular}{lcccc}
\hline & \multicolumn{4}{c}{ Quartile } \\
\cline { 2 - 5 } & $0-25 \%$ & $26-50 \%$ & $51-75 \%$ & $76-100 \%$ \\
\hline Grazing & & & \\
Lactations, n & 6,191 & 18,653 & 25,737 & 29,844 \\
Cows, n & 2,858 & 7,981 & 10,569 & 11,708 \\
Sires, n & 692 & 1,374 & 1,733 & 1,879 \\
Mean age of cows, yr & 2.43 & 2.43 & 2.43 & 2.43 \\
Mean age of sires, yr & 9.54 & 9.80 & 9.85 & 9.85 \\
Confinement & & & 33,777 & 27,335 \\
Lactations, n & 20,696 & 33,808 & 14,134 & 11,420 \\
Cows, n & 7,832 & 13,399 & 2,395 & 2,107 \\
Sires, n & 1,796 & 2,360 & 2.34 & 2.34 \\
Mean age of cows, yr & 2.41 & 2.33 & 9.82 & 9.99 \\
Mean age of sires, yr & 10.20 & 9.82 & & 870 \\
Relationship matrix & & & & \\
Sires common to grazing and confinement & 366 & 769 & 12,945 & 11,922 \\
Other ancestors & 7,489 & 10,643 & & \\
\hline
\end{tabular}

that of Kearney et al. (2004a); however, we did not include Wisconsin herds and we included updated information for all herds.

Linear regression (SAS v8.9, SAS Institute, Cary, NC) of MEM, MEP, MEF, and LSCS on USDA-DHIA sire's PTA was carried out for all cows in both $\mathrm{C}$ and $\mathrm{G}$ herds using the following model:

$$
\mathrm{y}_{\mathrm{ijklm}}=\mathrm{h}_{\mathrm{i}}+\mathrm{ys}_{\mathrm{j}}+\mathrm{ap}_{\mathrm{k}}+\beta \mathrm{PTA}_{\mathrm{l}}+\mathrm{e}_{\mathrm{ijklm}},
$$

where $\mathrm{y}_{\mathrm{ijklm}}=\mathrm{MEM}, \mathrm{MEP}, \mathrm{MEF}$, or LSCS for the mth record for cow 1 , in herd $i$, calving in year-season $j$, in age-parity class $\mathrm{k}, \mathrm{h}_{\mathrm{i}}=$ fixed effect of herd $\mathrm{i}, \mathrm{ys}_{\mathrm{j}}=$ fixed effect of year-season of calving $\mathrm{j}, \mathrm{ap}_{\mathrm{k}}=$ fixed effect of age-parity class $\mathrm{k}, \beta=$ linear regression coefficient of daughter MEM, MEP, MEF, or LSCS on sire PTA, $\mathrm{PTA}_{1}=$ USDA-DHIA PTA for MEM, MEP, MEF, or LSCS of the sire of cow 1 , and $\mathrm{e}_{\mathrm{ijklm}}=$ random residual.

Age-parity $\left(a p_{k}\right)$ accounts for variation due to the age of each cow within parity and is necessary despite the use of mature-equivalent records, which are determined by use of regionally derived factors that may not entirely account for age effects within a particular herd.

Herds were sorted by within-herd variation and then divided into quartiles based on variance for MEM. The number of lactations, cows, sires, and mean age of cows and sires for each variance quartile is detailed in Table 2 .

Regression coefficients were obtained for MEM, MEP, $\mathrm{MEF}$, and LSCS separately for variance quartiles based on variance for MEM, to investigate the adequacy of sires' PTA in predicting daughter performance in $\mathrm{G}$ and $\mathrm{C}$ herds with different variance. The previous model was fit within each variance quartile for $\mathrm{G}$ and $\mathrm{C}$ herds.

To account for heteroscedasticity, yield deviations within herd for MEM, MEP, MEF, and LSCS were stan- dardized to the population average within-herd standard deviation in 1997 (Wiggans and VanRaden, 1991). An adjusted within-herd standard deviation for MEM, MEP, MEF, and LSCS was obtained as

$$
\operatorname{sd}_{\mathrm{ijk}}^{*}=\left[\left(\mathrm{df}_{\mathrm{ijk}} \times \mathrm{sd}_{\mathrm{ijk}}\right)+\left(20 \times \overline{s d}_{\text {Base Year }}\right)\right] /\left(20+\mathrm{df}_{\mathrm{ijk}}\right),
$$

where $\mathrm{sd}_{\mathrm{ijk}}^{*}=$ within-herd standard deviation adjusted toward across-herd standard deviation according to herd size; $d f_{i j k}=$ total degrees of freedom for MEM, MEP, MEF, or LSCS for herd i, year j, and parity k; $\mathrm{sd}_{\mathrm{ijk}}=$ standard deviation for herd $\mathrm{i}$, year $\mathrm{j}$, and parity $\mathrm{k}$ for MEM, MEP, MEF, or LSCS; and $\overline{s d}_{\text {Base Year }}=$ the average standard deviation for MEM, MEP, MEF, or LSCS for the base year of 1996 for parity 1 and 1997 for parity 2 and later parities.

Then, individual lactation records were standardized according to

$$
\mathrm{t}_{\mathrm{m}}=\left(\mathrm{y}_{\mathrm{m}}-\mathrm{x}_{\mathrm{ijk}}\right) \times\left(\mathrm{sd}^{*} / \mathrm{sd}_{\mathrm{ijk}}\right)+\mathrm{x}_{\mathrm{ijk}}
$$

where $t_{m}=$ adjusted values of the mth record of MEM (AMEM), MEP (AMEP), MEF (AMEF), or LSCS (ALSCS); $y_{m}=m$ th record for MEM, MEP, MEF, or LSCS; $\mathrm{x}_{\mathrm{ijk}}=$ the within-herd mean of MEM, MEP, MEF, or LSCS for herd i, year $\mathrm{j}$, and parity $\mathrm{k}$; $\mathrm{sd}_{\mathrm{i}}=$ the standard deviation within-herd $\mathrm{i}$; and $\mathrm{sd}^{*}=$ within-herd standard deviation adjusted toward across-herd standard deviation according to herd size.

The base years of 1996 and 1997 were selected because they represented the middle time point in the data set, with years in the data set ranging between 1990 and 2003. This transformation was chosen because it is similar to the transformation used in the national genetic evaluations carried out by the USDA, 
Table 3. Numbers of records and means (standard deviations in parentheses) for grazing $(G)$ and confinement (C) herds for the overall data set and by parity for mature-equivalent milk (MEM), mature-equivalent protein (MEP), mature-equivalent fat (MEF), and lactation-average SCS (LSCS)

\begin{tabular}{|c|c|c|c|c|c|c|c|}
\hline Parity & Treatment & Records, $\mathrm{n}^{1}$ & MEM, kg & $\mathrm{MEP}, \mathrm{kg}$ & $\mathrm{MEF}, \mathrm{kg}$ & Records, $\mathrm{n}^{2}$ & LSCS \\
\hline \multirow[t]{2}{*}{ All } & $\mathrm{G}$ & 86,752 & $\begin{array}{c}8,462.64 \\
(1,996.33)\end{array}$ & $\begin{array}{c}264.89 \\
(61.72)\end{array}$ & $\begin{array}{c}288.08 \\
(75.43)\end{array}$ & 81,983 & $\begin{array}{c}3.50 \\
(1.54)\end{array}$ \\
\hline & $\mathrm{C}$ & 125,394 & $\begin{array}{c}9,811.61 \\
(2,070.86)\end{array}$ & $\begin{array}{c}306.40 \\
(63.06)\end{array}$ & $\begin{array}{c}350.29 \\
(78.93)\end{array}$ & 115,531 & $\begin{array}{c}3.25 \\
(1.56)\end{array}$ \\
\hline \multirow[t]{2}{*}{1} & $\mathrm{G}$ & 34,931 & $\begin{array}{c}8,302.08 \\
(1,893.83)\end{array}$ & $\begin{array}{c}259.15 \\
(58.70)\end{array}$ & $\begin{array}{c}281.12 \\
(72.20)\end{array}$ & 32,918 & $\begin{array}{c}3.18 \\
(1.40)\end{array}$ \\
\hline & $\mathrm{C}$ & 50,700 & $\begin{array}{c}9,726.58 \\
(1,991.42)\end{array}$ & $\begin{array}{c}303.68 \\
(60.80)\end{array}$ & $\begin{array}{c}346.05 \\
(75.34)\end{array}$ & 46,437 & $\begin{array}{c}2.95 \\
(1.44)\end{array}$ \\
\hline \multirow[t]{2}{*}{2} & $\mathrm{G}$ & 24,055 & $\begin{array}{c}9,031.27 \\
(2,050.08)\end{array}$ & $\begin{array}{c}271.16 \\
(62.77)\end{array}$ & $\begin{array}{c}295.71 \\
(76.88)\end{array}$ & 22,685 & $\begin{array}{c}3.43 \\
(1.47)\end{array}$ \\
\hline & $\mathrm{C}$ & 34,863 & $\begin{array}{c}10,055.84 \\
(2,120.23)\end{array}$ & $\begin{array}{c}313.99 \\
(63.89)\end{array}$ & $\begin{array}{c}358.29 \\
(80.79)\end{array}$ & 32,138 & $\begin{array}{c}3.15 \\
(1.49)\end{array}$ \\
\hline \multirow[t]{2}{*}{3} & G & 27,766 & $\begin{array}{c}8,486.39 \\
(2,056.48)\end{array}$ & $\begin{array}{c}266.68 \\
(63.83)\end{array}$ & $\begin{array}{c}290.21 \\
(77.35)\end{array}$ & 26,380 & $\begin{array}{c}3.97 \\
(1.64)\end{array}$ \\
\hline & $\mathrm{C}$ & 39,831 & $\begin{array}{c}9,706.08 \\
(2,108.50)\end{array}$ & $\begin{array}{c}303.24 \\
(64.58)\end{array}$ & $\begin{array}{c}348.69 \\
(81.19)\end{array}$ & 36,956 & $\begin{array}{c}3.70 \\
(1.66)\end{array}$ \\
\hline
\end{tabular}

${ }^{1}$ Number of records for MEM, MEP, and MEF.

${ }^{2}$ Number of records for LSCS.

which matches our objective to determine if the transformation accounts for the different environments between $\mathrm{G}$ and $\mathrm{C}$ herds in the United States. Following transformation, the previously described regression equation was repeated, but with AMEM, AMEP, AMEF, and ALSCS as dependent variables.

The (co)variance component estimation package, VCE4 (Neumaier and Groeneveld, 1998), was used to calculate heritabilities of traits within environments and genetic correlations of traits between environments before and after transformation. Restricted maximum likelihood (REML) using analytical gradients was used for these procedures. A bivariate animal model was used to calculate variance components, and the same trait in different environments was considered to be a different trait. Models were fit separately for the quartiles based on within-herd variance for MEM. The algebraic form of the animal model was as follows:

$$
\mathrm{y}_{\mathrm{ijklm}}=\mathrm{hys}_{\mathrm{i}}+\mathrm{a}_{\mathrm{j}}+\mathrm{pe}_{\mathrm{k}}+\mathrm{ap}_{\mathrm{l}}+\mathrm{e}_{\mathrm{ijklm}},
$$

where $\mathrm{y}_{\mathrm{ijk} \mathrm{k}}=$ the mth MEM, MEP, MEF, or LSCS record for animal $\mathrm{j}$ in permanent environment $\mathrm{k}$, herdyear-season i, and in age-parity class $l$ either adjusted or unadjusted for heteroscedasticity; hys $\mathrm{s}_{\mathrm{i}}=$ fixed effect of herd-year-season $i ; a_{j}=$ random additive genetic effect of animal j; $\mathrm{pe}_{\mathrm{k}}=$ random permanent environment effect $\mathrm{k}$; $\mathrm{ap}_{\mathrm{l}}=$ fixed effect of age-parity class $\mathrm{l}$; and $\mathrm{e}_{\mathrm{ijklm}}=$ random residual effect.

Separate numerator relationship matrices were utilized for each quartile. The number of sires with daughters in the relationship matrices and the number of other relatives in the relationship matrices is outlined in Table 2. Unknown parent groups were assigned as in Kearney et al. (2004a). Heritabilities for each trait were calculated as $\hat{\sigma}_{a}^{2} / \hat{\sigma}_{p}^{2}$ and genetic correlations were calculated as

$$
\hat{r}_{g}=\frac{\hat{\sigma}_{a(G) a(C)}}{\sqrt{\hat{\sigma}_{a(G)}^{2} \hat{\sigma}_{a(C)}^{2}}}
$$

where $\hat{\sigma}_{a}^{2}=$ estimate of additive genetic variance, $\hat{\sigma}_{P}^{2}=$ $\hat{\sigma}_{a}^{2}+\hat{\sigma}_{p e}^{2}+\hat{\sigma}_{e}^{2} ; \hat{\sigma}_{p e}^{2}=$ estimate of permanent environmental variance; $\hat{\sigma}_{e}^{2}=$ estimate of residual variance; $\hat{r}_{g}=$ estimate of genetic correlation; $\hat{\sigma}_{a(G) a(C)}=$ estimate of the additive genetic covariance of traits in $\mathrm{G}$ and $\mathrm{C}$; $\hat{\sigma}_{a(G)}^{2}=$ estimate of the additive genetic variance of traits in G; and $\hat{\sigma}_{a(C)}^{2}=$ estimate of the additive genetic variance of traits in $\mathrm{C}$.

\section{RESULTS AND DISCUSSION}

Means, standard deviations, and number of records for MEM, MEP, MEF, and LSCS before transformation are displayed in Table 3. The means for MEM, MEP, and MEF were higher for the $\mathrm{C}$ herds than the $\mathrm{G}$ herds for the overall data set and by parity, as expected. Production yields were lower for the third parity for both $\mathrm{G}$ and $\mathrm{C}$ herds; a partial explanation is that the third parity includes parity 3 and greater. The mean LSCS for $\mathrm{C}$ herds was lower than that of $\mathrm{G}$ herds for the overall data set and for each parity. A reason for $G$ herds having a higher LSCS may be that 307 of the $366 \mathrm{G}$ herds were from the southern states of Mississippi and Louisiana, where high temperatures may be 
Table 4. Summary distribution statistics for all traits for grazing and confinement herds for the overall data set, for actual and adjusted mature-equivalent milk (MEM and AMEM), mature-equivalent protein (MEP and AMEP), mature-equivalent fat (MEF and AMEF), and lactation-average SCS (LSCS and ALSCS)

\begin{tabular}{lrrrrrrrr}
\hline & \multicolumn{7}{c}{ Trait } \\
\cline { 2 - 8 } & MEM & AMEM & MEP & AMEP & MEF & AMEF & LSCS & ALSCS \\
\hline Grazing & & & & & & & & \\
Skewness & 0.07 & -0.01 & 0.03 & -0.04 & 0.35 & 0.23 & 0.49 & 0.43 \\
Kurtosis & 0.07 & -0.05 & 0.08 & -0.05 & 0.24 & 0.04 & -0.01 & -0.18 \\
CV & 23.51 & 23.39 & 23.23 & 22.93 & 26.06 & 26.16 & 43.88 & 43.12 \\
Confinement & & & & & & & & \\
$\quad$ Skewness & -0.14 & -0.13 & -0.18 & -0.16 & 0.02 & -0.01 & 0.59 & 0.51 \\
Kurtosis & 0.17 & 0.03 & 0.29 & 0.12 & 0.06 & -0.03 & -0.02 & -0.20 \\
CV & 20.65 & 20.07 & 20.10 & 19.53 & 21.73 & 21.23 & 47.92 & 46.49 \\
\hline
\end{tabular}

the cause of a higher incidence of environmental mastitis, thus causing elevated LSCS (Schutz et al., 1994). Standard deviations for MEM, MEP, and MEF were also larger for $\mathrm{C}$ herds than $\mathrm{G}$ herds in each category. Increased variance in $\mathrm{C}$ herds indicated that further consideration of the degree of heteroscedasticity is warranted.

Values for skewness, kurtosis, and coefficients of variation $(\mathbf{C V})$ for $\mathrm{G}$ and $\mathrm{C}$ herds for all traits before and after the transformation to reduce heteroscedasticity are shown in Table 4. Distributions for G and C herds were assumed to be approximately normal, because skewness and kurtosis estimates were very close to zero. The transformation did not affect the symmetry of the distribution to any great extent, as all values remained very close to zero. In all cases, skewness and kurtosis were reduced by the transformation; although CV were not greatly affected because within-herd variance may have either been expanded or contracted.

The CV for the overall data set were higher for $G$ herds than $\mathrm{C}$ herds in both nontransformed and transformed data sets for MEM, MEF, and MEP. Larger herds tended to have the most variation, but that relationship was more pronounced for G than for C. Coefficients of variation were found to be less for LSCS and adjusted LSCS in G herds than C herds. Despite greater variance in $\mathrm{C}$ herds (Table 3), CV was lower, likely arising from an underlying mean-variance relationship. In $\mathrm{G}$ herds, the transformation reduced CV for milk, protein, and LSCS; however, it was increased for fat. In $\mathrm{C}$ herds $\mathrm{CV}$ decreased for all 4 traits. This indicates that a transformation for heteroscedasticity slightly decreased variance relative to the mean.

Means of PTA for milk (PTAM) of G herds in variance quartiles analysis showed that PTAM increased with within-herd variance of MEM (Table 5). This indicated that bulls with higher producing daughters were in the higher variance herds. Standard deviations of these values were similar, and the maximum PTAM values increased as quartiles fluctuated. In C herds, PTAM values fluctuated among variance quartiles. Standard deviations were similar, and the maximum PTAM values were shown to fluctuate. Fluctuation of PTAM on $\mathrm{C}$ herds may be an artifact of sampling of herds.

Distribution statistics are shown for the variance quartiles based on MEM in Table 6. Skewness was reduced and kurtosis usually tended toward zero because of transforming the data to reduce heteroscedasticity. The CV increased following standardization of within-herd variance for the first 2 quartiles for $\mathrm{G}$ herds and for the first quartile for the $\mathrm{C}$ herds. The CV were reduced for all other quartiles for $\mathrm{G}$ and $\mathrm{C}$ herds, resulting in a reduction in the variation range.

Means and standard deviations increased for MEM, MEP, and MEF from the lowest to the highest quartiles for $\mathrm{C}$ and $\mathrm{G}$ herds (Table 7). Lactation-average SCS had a low correlation (data not shown) with MEM, $\mathrm{MEP}$, and MEF, resulting in a fluctuating pattern for LSCS means and standard deviations. Adjustment of within-herd variance was based on within-herd variance for MEM; as a result, LSCS did not follow the similar trends for means and standard deviations of MEM, MEP, and MEF.

Means and standard deviations were calculated for AMEM, AMEP, AMEF, and ALSCS for variance quartiles and are shown in Table 8 . The mean and

Table 5. Predicted transmitting ability values of sires for matureequivalent milk (MEM) for variance quartiles based on MEM

\begin{tabular}{lrccc}
\hline & $\begin{array}{c}\text { Mean } \\
(\mathrm{kg})\end{array}$ & $\begin{array}{c}\text { SD } \\
(\mathrm{kg})\end{array}$ & $\begin{array}{c}\text { Minimum } \\
(\mathrm{kg})\end{array}$ & $\begin{array}{c}\text { Maximum } \\
(\mathrm{kg})\end{array}$ \\
\hline Grazing & & & & \\
$0-25 \%$ & -64 & 649 & $-3,029$ & 1,912 \\
$26-50 \%$ & 10 & 672 & $-3,042$ & 2,358 \\
$51-75 \%$ & 33 & 671 & $-3,892$ & 2,129 \\
$76-100 \%$ & 105 & 658 & $-4,087$ & 2,724 \\
Confinement & & & & \\
$0-25 \%$ & 86 & 635 & $-2,883$ & 2,142 \\
26-50\% & 142 & 638 & $-2,852$ & 2,358 \\
$51-75 \%$ & 98 & 655 & $-3,188$ & 2,724 \\
$76-100 \%$ & 181 & 641 & $-3,395$ & 2,358 \\
\hline
\end{tabular}


Table 6. Summary distribution statistics for grazing and confinement herds for variance quartiles, for actual and adjusted mature-equivalent milk (MEM and AMEM), mature-equivalent protein (MEP and AMEP), mature-equivalent fat (MEF and AMEF), and lactation-average SCS (LSCS and ALSCS)

\begin{tabular}{|c|c|c|c|c|c|c|c|c|}
\hline & MEM & AMEM & MEP & AMEP & MEF & AMEF & LSCS & ALSCS \\
\hline \multicolumn{9}{|c|}{$0-25 \%$ variance quartile } \\
\hline \multicolumn{9}{|l|}{ Grazing } \\
\hline Skewness & 0.04 & 0.01 & 0.07 & 0.04 & 0.30 & 0.21 & 0.46 & 0.40 \\
\hline Kurtosis & 0.001 & -0.01 & -0.10 & -0.11 & 0.10 & -0.002 & 0.07 & -0.12 \\
\hline $\mathrm{CV}$ & 20.00 & 21.79 & 20.26 & 21.80 & 23.14 & 25.07 & 46.31 & 45.33 \\
\hline \multicolumn{9}{|l|}{ Confinement } \\
\hline Skewness & -0.13 & -0.13 & -0.18 & -0.17 & 0.09 & 0.03 & 0.63 & 0.55 \\
\hline Kurtosis & 0.09 & 0.01 & 0.08 & -0.03 & 0.24 & 0.06 & 0.001 & -0.22 \\
\hline $\mathrm{CV}$ & 18.95 & 19.60 & 18.7 & 19.27 & 20.68 & 21.04 & 50.09 & 48.49 \\
\hline \multicolumn{9}{|c|}{$26-50 \%$ variance quartile } \\
\hline Grazing & & & & & & & & \\
\hline Skewness & -0.03 & -0.07 & -0.07 & -0.08 & 0.19 & 0.11 & 0.50 & 0.44 \\
\hline Kurtosis & 0.15 & 0.04 & 0.14 & 0.05 & 0.09 & -0.01 & 0.02 & -0.16 \\
\hline CV & 21.14 & 22.09 & 20.79 & 21.69 & 23.04 & 24.4 & 44.26 & 43.28 \\
\hline \multicolumn{9}{|l|}{ Confinement } \\
\hline Skewness & -0.19 & -0.17 & -0.28 & -0.24 & 0.05 & -0.001 & 0.59 & 0.52 \\
\hline Kurtosis & 0.28 & 0.13 & 0.41 & 0.22 & 0.32 & 0.13 & -0.04 & -0.21 \\
\hline $\mathrm{CV}$ & 18.71 & 18.60 & 17.88 & 17.84 & 19.90 & 19.82 & 48.10 & 46.75 \\
\hline \multicolumn{9}{|c|}{$51-75 \%$ variance quartile } \\
\hline Grazing & & & & & & & & \\
\hline Skewness & -0.08 & -0.09 & -0.13 & -0.15 & 0.20 & 0.12 & 0.46 & 0.42 \\
\hline Kurtosis & 0.12 & 0.05 & 0.19 & 0.08 & 0.19 & 0.07 & -0.07 & -0.22 \\
\hline $\mathrm{CV}$ & 22.49 & 22.60 & 22.15 & 22.12 & 24.80 & 25.3 & 43.34 & 42.60 \\
\hline \multicolumn{9}{|l|}{ Confinement } \\
\hline Skewness & -0.12 & -0.11 & -0.11 & -0.10 & 0.10 & 0.07 & 0.61 & 0.53 \\
\hline Kurtosis & 0.20 & 0.10 & 0.40 & 0.25 & 0.25 & 0.17 & 0.07 & -0.16 \\
\hline CV & 21.56 & 20.76 & 20.92 & 20.13 & 22.71 & 22.02 & 47.94 & 46.53 \\
\hline \multicolumn{9}{|c|}{$76-100 \%$ variance quartile } \\
\hline Grazing & & & & & & & & \\
\hline Skewness & -0.17 & -0.19 & -0.22 & -0.22 & 0.18 & 0.11 & 0.51 & 0.44 \\
\hline Kurtosis & 0.12 & 0.03 & 0.22 & 0.10 & 0.06 & -0.06 & 0.01 & -0.17 \\
\hline $\mathrm{CV}$ & 23.03 & 21.82 & 22.27 & 20.98 & 25.5 & 24.61 & 43.56 & 43.00 \\
\hline \multicolumn{9}{|l|}{ Confinement } \\
\hline Skewness & -0.18 & -0.15 & -0.21 & -0.17 & 0.13 & 0.07 & 0.56 & 0.48 \\
\hline Kurtosis & 0.19 & 0.06 & 0.26 & 0.11 & 0.09 & -0.02 & -0.01 & -0.21 \\
\hline CV & 22.60 & 20.82 & 22.28 & 20.53 & 24.65 & 22.94 & 45.98 & 44.51 \\
\hline
\end{tabular}

Table 7. Means (standard deviations in parentheses) for variance quartiles [based on variance of mature-equivalent milk (MEM)] for MEM, mature-equivalent protein (MEP), mature-equivalent fat (MEF), and lactation-average SCS (LSCS)

\begin{tabular}{ccccc}
\hline Quartile & MEM $(\mathrm{kg})$ & MEP $(\mathrm{kg})$ & MEF $(\mathrm{kg})$ & LSCS \\
\hline Grazing & & & & \\
$0-25 \%$ & $7,067.72$ & 219.41 & 236.06 & 3.11 \\
& $(1,365.14)$ & $(43.16)$ & $(51.45)$ & $(1.37)$ \\
$26-50 \%$ & $7,762.56$ & 239.53 & 258.70 & 3.17 \\
& $(1,584.75)$ & $(48.64)$ & $(57.89)$ & $(1.39)$ \\
$51-75 \%$ & $8,299.04$ & 258.79 & 280.43 & 3.23 \\
& $(1,808.98)$ & $(55.67)$ & $(68.12)$ & $(1.41)$ \\
$76-100 \%$ & $9,026.14$ & 283.82 & 308.78 & 3.16 \\
& $(1,987.72)$ & $(60.39)$ & $(77.29)$ & $(1.40)$ \\
Confinement & & & & \\
$0-25 \%$ & $9,022.37$ & 280.45 & 326.16 & 2.79 \\
& $(1,674.63)$ & $(51.86)$ & $(65.94)$ & $(1.41)$ \\
$26-50 \%$ & $9,631.72$ & 299.87 & 341.46 & 2.96 \\
& $(1,731.45)$ & $(51.74)$ & $(64.02)$ & $(1.44)$ \\
$51-75 \%$ & $9,847.42$ & 307.89 & 348.94 & 2.96 \\
& $(2,036.45)$ & $(61.85)$ & $(76.57)$ & $(1.44)$ \\
$76-100 \%$ & $10,273.55$ & 320.41 & 362.85 & 3.10 \\
& $(2,230.86)$ & $(68.50)$ & $(86.11)$ & $(1.46)$ \\
\hline
\end{tabular}

Table 8. Adjusted means (standard deviations in parentheses) for variance quartiles [based on variance of mature-equivalent milk (MEM)] percentile groups for adjusted MEM (AMEM), adjusted mature-equivalent protein (AMEP), adjusted mature-equivalent fat (AMEF), and adjusted lactation-average SCS (ALSCS)

\begin{tabular}{ccccc}
\hline Quartile & AMEM $(\mathrm{kg})$ & AMEP $(\mathrm{kg})$ & AMEF $(\mathrm{kg})$ & ALSCS \\
\hline Grazing & & & & \\
$0-25 \%$ & $7,067.72$ & 219.41 & 236.06 & 3.11 \\
& $(1,472.21)$ & $(45.94)$ & $(55.43)$ & $(1.34)$ \\
$26-50 \%$ & $7,762.56$ & 239.53 & 258.70 & 3.17 \\
& $(1,659.03)$ & $(50.75)$ & $(61.07)$ & $(1.37)$ \\
$51-75 \%$ & $8,299.04$ & 258.79 & 280.43 & 3.23 \\
& $(1,823.46)$ & $(55.81)$ & $(69.43)$ & $(1.39)$ \\
$76-100 \%$ & $9,026.14$ & 283.81 & 308.78 & 3.16 \\
& $(1,907.67)$ & $(57.91)$ & $(75.28)$ & $(1.38)$ \\
Confinement & & & & \\
$0-25 \%$ & $9,022.37$ & 280.45 & 326.16 & 2.79 \\
& $(1,715.44)$ & $(52.95)$ & $(66.73)$ & $(1.37)$ \\
$26-50 \%$ & $9,631.72$ & 299.87 & 341.46 & 2.96 \\
& $(1,721.01)$ & $(51.51)$ & $(63.90)$ & $(1.40)$ \\
$51-75 \%$ & $9,847.42$ & 307.89 & 348.94 & 2.96 \\
& $(1,962.67)$ & $(59.64)$ & $(74.39)$ & $(1.40)$ \\
$76-100 \%$ & $10,273.55$ & 320.41 & 362.85 & 3.10 \\
& $(2,085.30)$ & $(63.98)$ & $(81.22)$ & $(1.41)$ \\
\hline
\end{tabular}


Table 9. Regression of mature-equivalent milk (MEM), mature-equivalent protein (MEP), mature-equivalent fat (MEF), and lactation-average SCS (LSCS) on sires' PTA for variance quartiles (based on the variance of MEM) for grazing and confinement herds

\begin{tabular}{lllll}
\hline Quartile & \multicolumn{1}{c}{ MEM } & \multicolumn{1}{c}{ MEP } & \multicolumn{1}{c}{ MEF } & LSCS \\
\hline Grazing & & & & \\
$0-25 \%$ & $0.466(0.081)^{* *}$ & $0.562(0.088)^{* *}$ & $0.516(0.072)^{* * *}$ & $0.971(0.134)$ \\
$26-50 \%$ & $0.747(0.058)^{* *}$ & $0.746(0.063)^{* *}$ & $0.697(0.051)^{* *}$ & $0.852(0.082)$ \\
$51-75 \%$ & $0.800(0.056)^{* *}$ & $0.841(0.062)^{* *}$ & $0.810(0.049)^{* *}$ & $0.916(0.071)$ \\
$76-100 \%$ & $0.877(0.062)^{*}$ & $0.893(0.067)$ & $0.819(0.043)^{* *}$ & $0.818(0.048)^{* *}$ \\
Confinement & & & & \\
$0-25 \%$ & $0.869(0.061)^{* *}$ & $0.866(0.064)^{* *}$ & $0.796(0.059)^{* *}$ & $0.988(0.081)$ \\
$26-50 \%$ & $0.878(0.053)^{* *}$ & $0.993(0.056)$ & $0.913(0.048)^{* *}$ & $1.124(0.063)$ \\
$51-75 \%$ & $1.094(0.054)$ & $1.038(0.058)$ & $0.949(0.050)$ & $0.953(0.061)$ \\
$76-100 \%$ & $1.097(0.070)$ & $1.165(0.075)^{*}$ & $1.078(0.067)$ & $0.981(0.070)$ \\
\hline
\end{tabular}

*Significantly different from $1(P<0.05)$;**significantly different from $1(P<0.01)$.

standard deviation trends were similar to those before the transformation for within-herd phenotypic heteroscedasticity (Table 7).

The transformation succeeded in reducing withinherd variance, as is evident by the decrease in the standard deviation range. The quartiles with the lowest variances had an increase in their standard deviations, and quartiles with high variances had a decrease in their standard deviations. As a result, the degree of heteroscedasticity was reduced.

Regression coefficients of unadjusted MEM, MEP, MEF, and LSCS on sires' PTA for variance quartiles are shown in Table 9. Although regression coefficients deviated from the expected value of 1.0 , all ranged from 0.466 to 1.165 . Regression coefficients for variance quartiles of G herds for MEM, MEP, MEF, and LSCS were all less than 1.0, suggesting that PTA overestimated production yields and LSCS. In G herds, regression coefficients increased from the lowest quartile to the highest quartile for MEM, MEP, and MEF. The first 3 quartiles for MEP were significantly less than 1 $(P<0.01)$; however, the fourth quartile with a regression coefficient of 0.893 was not significantly different than 1. Regression coefficients were significantly less than $1(P<0.01)$ for all quartiles, which suggests that sires' PTA for fat consistently overestimated MEF in all quartiles.

Regression coefficients for unadjusted MEM in C herds were significantly less than unity in the first 2 quartiles $(P<0.01)$. The third and fourth quartiles' coefficients were greater, although not significantly different than 1. Similar results were found in Canadian herds (Boettcher et al., 2003). Mature-equivalent protein in $\mathrm{C}$ herds had regression coefficients $<1$ for the first 2 quartiles and $>1$ in the third and fourth quartiles, suggesting that sires' PTA overestimated MEF. The first and second quartile's regression coefficient of 0.866 was significantly $<1(P<0.01)$ and the regression coeffi- cient of the fourth quartile was significantly $>1$ ( $P<$ $0.05)$.

Regression coefficients increased in both $\mathrm{G}$ and $\mathrm{C}$ herds from the lower quartiles to higher quartiles. This suggests that current sires' PTA overestimated production for herds in low quartiles and that a separate evaluation with reporting of PTA may be justifiable for herds with low phenotypic variance quartiles vs. those with high phenotypic variance. Alternatively, standardization for heteroscedasticity could be applied.

Table 10 has heritabilities, ratios of permanent environmental variation to phenotypic variation, and genetic correlations for MEM, MEP, MEF, and LSCS for variance quartiles based on MEM variance. Heritability of MEM varied between 0.15 and 0.18 for G herds, and 0.14 and 0.20 for $\mathrm{C}$ herds. The ratio of permanent environmental variation to phenotypic variation ranged from 0.20 to 0.23 for $\mathrm{G}$ herds with a lower range (0.23 to 0.27 ) for $\mathrm{C}$ herds. Values for genetic correlations were diverse. The first quartile had a correlation of 0.21 with a standard error of 0.22 . The second quartile had a correlation of 0.77 ; the third quartile had a correlation of 0.97 , whereas the fourth quartile had a genetic correlation of 0.86 . Heritabilities for MEM were similar to those calculated in 2 previous studies that split data sets according to phenotypic variance (Hill et al., 1983; Lofgren et al., 1985). Production levels usually increased as phenotypic variance of the trait increased, and herds with higher production had higher heritabilities (Legates, 1962). Other studies found that milk had a higher heritability in high-variance herds compared with low-variance herds (Hill et al., 1983; Lofgren et al., 1985; de Veer et al., 1987; Van Vleck and Dong, 1988). In this study for $G$ herds, the lowest variance quartile for milk had a heritability of 0.15 and this increased to 0.18 for the second quartile; then, a negligible drop to 0.17 was found for the third and fourth quartiles. Increasing permanent environmental varia- 
Table 10. Heritability $\left(h^{2}\right)$, ratio of permanent environment variance to phenotypic variance $\left(c^{2}\right)$, and genetic correlation ( $\left.\mathrm{r}_{\text {confinement,grazing }}\right)$ with standard errors in parentheses for mature-equivalent milk (MEM), matureequivalent protein (MEP), mature-equivalent fat (MEF), and lactation-average SCS (LSCS) for variance quartile analysis based on variance MEM for grazing and confinement herds

\begin{tabular}{|c|c|c|c|c|c|c|}
\hline \multirow[b]{2}{*}{ Trait } & \multirow[b]{2}{*}{ Quartile $^{1}$} & \multicolumn{2}{|c|}{ Grazing } & \multicolumn{2}{|c|}{ Confinement } & \multirow[b]{2}{*}{$r_{\text {confinement,grazing }}$} \\
\hline & & $h^{2}$ & $c^{2}$ & $\mathrm{~h}^{2}$ & $c^{2}$ & \\
\hline \multirow[t]{4}{*}{ MEM } & 1 & $0.15(0.03)$ & $0.23(0.03)$ & $0.16(0.02)$ & $0.27(0.02)$ & $0.21(0.22)$ \\
\hline & 2 & $0.18(0.02)$ & $0.21(0.02)$ & $0.15(0.01)$ & $0.27(0.01)$ & $0.77(0.07)$ \\
\hline & 3 & $0.17(0.01)$ & $0.20(0.01)$ & $0.20(0.01)$ & $0.23(0.01)$ & $0.97(0.04)$ \\
\hline & 4 & $0.17(0.01)$ & $0.21(0.01)$ & $0.14(0.01)$ & $0.26(0.01)$ & $0.86(0.05)$ \\
\hline \multirow[t]{4}{*}{ MEP } & 1 & $0.18(0.03)$ & $0.21(0.03)$ & $0.19(0.02)$ & $0.26(0.02)$ & $0.78(0.15)$ \\
\hline & 2 & $0.17(0.02)$ & $0.24(0.02)$ & $0.16(0.01)$ & $0.28(0.01)$ & $0.80(0.07)$ \\
\hline & 3 & $0.15(0.01)$ & $0.22(0.01)$ & $0.18(0.01)$ & $0.25(0.01)$ & $0.93(0.05)$ \\
\hline & 4 & $0.16(0.01)$ & $0.22(0.01)$ & $0.16(0.01)$ & $0.25(0.01)$ & $0.85(0.05)$ \\
\hline \multirow[t]{4}{*}{ MEF } & 1 & $0.23(0.03)$ & $0.14(0.03)$ & $0.24(0.02)$ & $0.24(0.02)$ & $1.00(0.00)^{2}$ \\
\hline & 2 & $0.22(0.02)$ & $0.17(0.02)$ & $0.23(0.01)$ & $0.22(0.01)$ & $0.84(0.06)$ \\
\hline & 3 & $0.18(0.01)$ & $0.18(0.01)$ & $0.23(0.01)$ & $0.20(0.01)$ & $0.99(0.02)$ \\
\hline & 4 & $0.17(0.01)$ & $0.20(0.01)$ & $0.17(0.01)$ & $0.23(0.01)$ & $0.87(0.05)$ \\
\hline \multirow[t]{4}{*}{ LSCS } & 1 & $0.15(0.03)$ & $0.18(0.03)$ & $0.13(0.01)$ & $0.24(0.01)$ & $0.78(0.16)$ \\
\hline & 2 & $0.08(0.02)$ & $0.27(0.01)$ & $0.11(0.01)$ & $0.22(0.01)$ & $0.98(0.08)$ \\
\hline & 3 & $0.16(0.01)$ & $0.19(0.01)$ & $0.14(0.01)$ & $0.20(0.01)$ & $0.78(0.06)$ \\
\hline & 4 & $0.10(0.01)$ & $0.24(0.01)$ & $0.10(0.01)$ & $0.24(0.01)$ & $0.96(0.05)$ \\
\hline
\end{tabular}

${ }^{1}$ Quartiles: $1=0-25 \% ; 2=26-50 \% ; 3=51-75 \% ; 4=76-100 \%$.

${ }^{2}$ Standard error of 0.00 is an artifact of the calculation program (VCE 4.0).

tion will increase phenotypic variation, and if the additive genetic variation does not increase with permanent environmental variation, then heritability will be reduced. In C herds, no consistent trend for heritability of MEM was noticed. The heritability was similar for the first, second, and fourth quartiles. For the third quartile, heritability for MEM increased to 0.20 , but this result is not readily explained.

A genetic correlation has been considered to be of biological importance when the correlation has a value $<0.80$ (Robertson et al., 1960). Although the exact level of correlation to indicate such a relationship is debatable, there is evidence that a $\mathrm{G} \times \mathrm{E}$ was present between the lowest quartiles of the $\mathrm{G}$ and $\mathrm{C}$ herds with a genetic correlation of 0.21 . Even though this has a standard error of 0.22 , it is far less than 0.80 and may be regarded as biologically important. The genetic correlation increased to 0.77 for the second quartile with a standard error of 0.07. A $\mathrm{G} \times \mathrm{E}$ may be present for this quartile. At the minimum, a scaling effect is likely. For the third and fourth quartiles, the genetic correlations were 0.97 and 0.86 , respectively, which provides much less evidence for a $\mathrm{G} \times \mathrm{E}$ or scaling effect.

Heritability for MEP was calculated to be 0.18 for the first quartile in G herds; however, this decreased steadily to 0.16 in the fourth quartile, even though protein yield increased for G herds (Table 10). Permanent environmental variation does not seem to have a very clear effect on the heritability trend for MEP; this may be because the data set was divided according to the variance of MEM and the relationship between MEM and MEP, although strong, is not perfect. Heritabilities for MEP in C herds were highest for the first quartile with a value of 0.19 ; the heritability decreased to 0.16 for the second quartile, increased to 0.18 for the third quartile, and fell again to 0.16 for the fourth quartile. This occurred even though MEP yields increased in C herds as the variance quartiles increased. Changes in permanent environmental variation were small, with a range from 0.25 to 0.28 for $\mathrm{C}$ herds. Heritability trends such as these may be due to a relatively greater increase in phenotypic variance than additive genetic variance causing heritabilities to decrease.

Genetic correlations for MEP increased from 0.78 to 0.93 from the first to the third quartile with a decrease to 0.85 for the fourth quartile. A scaling effect may be present for the first quartile. This implies that production in the lowest quartile is largely controlled by the same genes; however, due to environmental effects, gene expression for the $G$ herds does not reach its full potential. Correlations for MEP were similar to that of other studies (Calus et al., 2002; Boettcher et al., 2003; Kearney et al., 2004a). The other quartiles with genetic correlations $\geq 0.80$ likely do not present evidence of detectable scaling effects or a $\mathrm{G} \times \mathrm{E}$.

Heritabilities for MEF decreased as quartile variances increased. The heritability for MEF in the first quartile was 0.23 ; however, by the fourth quartile this had decreased steadily to 0.17 , similar to that found by Kearney et al. (2004a). This occurs despite the increase 
Table 11. Regression of adjusted mature-equivalent milk (AMEM), adjusted mature-equivalent protein (AMEP), adjusted mature-equivalent fat (AMEF), and adjusted lactation-average SCS (ALSCS) on sires' PTA for variance quartiles (based on the variance of MEM) for grazing and confinement herds

\begin{tabular}{lllll}
\hline Quartile & AMEM & \multicolumn{1}{c}{ AMEP } & \multicolumn{1}{c}{ AMEF } & ALSCS \\
\hline Grazing & & & & \\
0-25\% & $0.542(0.093)^{* *}$ & $0.648(0.098)^{* *}$ & $0.634(0.083)^{* * *}$ & $0.961(0.131)$ \\
$26-50 \%$ & $0.811(0.062)^{* *}$ & $0.822(0.067)^{* *}$ & $0.774(0.056)^{* *}$ & $0.846(0.081)$ \\
$51-75 \%$ & $0.820(0.056)^{* *}$ & $0.862(0.062)^{* *}$ & $0.846(0.051)^{* *}$ & $0.901(0.069)$ \\
$76-100 \%$ & $0.816(0.058)^{* *}$ & $0.815(0.063)^{* *}$ & $0.784(0.055)^{* *}$ & $0.816(0.066)^{* *}$ \\
Confinement & & & & \\
$0-25 \%$ & $0.904(0.063)$ & $0.911(0.066)$ & $0.826(0.060)^{* *}$ & $0.979(0.078)$ \\
$26-50 \%$ & $0.884(0.052)^{*}$ & $1.010(0.056)$ & $0.908(0.048)$ & $1.096(0.061)$ \\
$51-75 \%$ & $1.033(0.051)$ & $0.982(0.054)$ & $0.911(0.048)$ & $0.923(0.059)$ \\
$76-100 \%$ & $1.007(0.064)$ & $1.042(0.068)$ & $0.988(0.061)$ & $0.957(0.067)$ \\
\hline
\end{tabular}

*Significantly different from $1(P<0.05)$;**significantly different from $1(P<0.01)$.

in fat yields (Table 7). A similar trend was observed for both heritability and permanent environmental variation for MEF in the $\mathrm{C}$ herds. The decrease in heritability may be explained by the increase in permanent environmental variation for $\mathrm{MEF}$ in $\mathrm{G}$ herds from the first quartile to the fourth quartile.

Compelling evidence for $\mathrm{G} \times \mathrm{E}$ was not observed for $\mathrm{MEF}$, as the genetic correlations were all greater than 0.80 . A scaling effect may be present for the second and fourth quartiles with genetic correlations of 0.84 and 0.87 , respectively.

Heritability of LSCS ranged between 0.08 and 0.16 for $\mathrm{G}$ herds and from 0.10 to 0.14 for $\mathrm{C}$ herds, which is similar to previous work (Kearney et al., 2004b). Trends in both the $\mathrm{G}$ and $\mathrm{C}$ herds showed that the heritability fluctuated from one quartile to the next. A similar pattern was observed for permanent environmental variation. These trends were quite different compared with those observed for MEM, MEP, and MEF, probably because quartiles were based on yield, and yield traits had higher correlations among each other than they did with LSCS. Lactation SCS had genetic correlations that varied between 0.78 and 0.98 for the variance quartile analysis, which fluctuated in a similar way as the heritabilities and permanent environmental variance.

Regression of AMEM, AMEF, AMEP, and ALSCS on sires' PTA was carried out for variance quartiles for $G$ and $\mathrm{C}$ herds (Table 11). Changes in regression coefficients were small $(<0.10)$ when compared with the regression coefficients for MEM, MEP, MEF, and LSCS before transformation (Table 9), and changes in standard errors were negligible. In G herds, the coefficients of regression increased for AMEM, AMEP, AMEF, and ALSCS when compared with regression coefficients for MEM, MEP, MEF, and LSCS (Table 9) for the first 3 quartiles, but they were still less than unity. This result suggests that by reducing the level of heteroscedasticity for these traits, sires' PTA overestimated production levels to a lesser extent for the first 3 quartiles. Regression coefficients for AMEM, AMEP, AMEF, and ALSCS decreased for the fourth quartile after the transformation was applied to the data. Accounting for heteroscedasticity reduced regression coefficients, thereby increasing the overestimation of sires' PTA on production, when compared with the data before transformation.

In $\mathrm{C}$ herds, regression coefficients increased for the first and second quartiles and decreased for the third and fourth quartiles for AMEM, AMEP, and AMEF when compared with data before transformation. As a result, overestimation of sires' PTA was evident for AMEM and AMEF for the first 2 quartiles and for AMEP for the first quartile. Adjusted AMEP because of the transformation is underestimated by sire's PTA with a value of 1.01 , which is not significantly different from 1 . For the third and fourth quartiles, underestimation of production levels by sires' PTA for AMEM, AMEP, and for the fourth quartile for AMEF is reduced. Because of the transformation, AMEP was overestimated by sires' PTA in the third quartile, and the level of overestimation was increased for AMEF in the third quartile. Regression coefficients for ALSCS were reduced by negligible proportions for all quartiles. Thus, it appears that the mild standardization only partially accounted for the large within-herd variation.

Heritabilities, ratios of permanent environmental variation to phenotypic variation, genetic correlations, and standard errors associated with these values were calculated for AMEM, AMEP, AMEF, and ALSCS for $\mathrm{G}$ and $\mathrm{C}$ herds, and are shown in Table 12. When compared with the corresponding values for the 4 traits before transformation (Table 10), it can be seen that accounting for heteroscedasticity did not change heritability, permanent environmental values or their standard errors by any significant amount. There was also no trend in the changes; some values increased, some decreased, and some were unchanged. Changes in genetic correlations and their standard errors for the 4 
Table 12. Heritability $\left(h^{2}\right)$, ratio of permanent environment variance to phenotypic variance $\left(c^{2}\right)$, and genetic correlation ( $r_{\text {confinement,grazing }}$ ) with standard errors in parentheses for adjusted mature-equivalent milk (AMEM), adjusted mature-equivalent protein (AMEP), adjusted mature-equivalent fat (AMEF), and adjusted lactation-average SCS (ALSCS) for variance quartile analysis based on variance MEM for grazing and confinement herds

\begin{tabular}{|c|c|c|c|c|c|c|}
\hline \multirow[b]{2}{*}{ Trait } & \multirow[b]{2}{*}{ Quartile $^{1}$} & \multicolumn{2}{|c|}{ Grazing } & \multicolumn{2}{|c|}{ Confinement } & \multirow[b]{2}{*}{$r_{\text {confinement,grazing }}$} \\
\hline & & $\mathrm{h}^{2}$ & $c^{2}$ & $\mathrm{~h}^{2}$ & $c^{2}$ & \\
\hline \multirow[t]{4}{*}{ AMEM } & 1 & $0.16(0.03)$ & $0.22(0.03)$ & $0.16(0.02)$ & $0.27(0.02)$ & $0.25(0.23)$ \\
\hline & 2 & $0.19(0.02)$ & $0.21(0.02)$ & $0.16(0.01)$ & $0.27(0.01)$ & $0.79(0.07)$ \\
\hline & 3 & $0.18(0.01)$ & $0.19(0.01)$ & $0.20(0.01)$ & $0.23(0.01)$ & $0.96(0.04)$ \\
\hline & 4 & $0.17(0.01)$ & $0.22(0.01)$ & $0.15(0.01)$ & $0.26(0.01)$ & $0.86(0.05)$ \\
\hline \multirow[t]{4}{*}{ AMEP } & 1 & $0.18(0.03)$ & $0.20(0.03)$ & $0.19(0.02)$ & $0.26(0.01)$ & $0.80(0.15)$ \\
\hline & 2 & $0.18(0.02)$ & $0.24(0.02)$ & $0.16(0.01)$ & $0.28(0.01)$ & $0.83(0.06)$ \\
\hline & 3 & $0.16(0.01)$ & $0.22(0.01)$ & $0.18(0.01)$ & $0.25(0.01)$ & $0.93(0.05)$ \\
\hline & 4 & $0.16(0.01)$ & $0.23(0.01)$ & $0.16(0.01)$ & $0.25(0.01)$ & $0.85(0.05)$ \\
\hline \multirow[t]{4}{*}{$\mathrm{AMEF}$} & 1 & $0.23(0.03)$ & $0.15(0.03)$ & $0.23(0.02)$ & $0.24(0.01)$ & $1.00(0.00)^{2}$ \\
\hline & 2 & $0.22(0.02)$ & $0.18(0.02)$ & $0.22(0.01)$ & $0.22(0.01)$ & $0.85(0.06)$ \\
\hline & 3 & $0.19(0.01)$ & $0.18(0.01)$ & $0.23(0.01)$ & $0.19(0.01)$ & $0.99(0.02)$ \\
\hline & 4 & $0.17(0.01)$ & $0.21(0.01)$ & $0.19(0.01)$ & $0.22(0.01)$ & $0.88(0.04)$ \\
\hline \multirow[t]{4}{*}{ ALSCS } & 1 & $0.14(0.03)$ & $0.18(0.03)$ & $0.13(0.01)$ & $0.23(0.01)$ & $0.81(0.16)$ \\
\hline & 2 & $0.08(0.02)$ & $0.27(0.01)$ & $0.12(0.01)$ & $0.21(0.01)$ & $0.96(0.08)$ \\
\hline & 3 & $0.15(0.01)$ & $0.19(0.01)$ & $0.14(0.01)$ & $0.19(0.01)$ & $0.77(0.06)$ \\
\hline & 4 & $0.10(0.01)$ & $0.24(0.01)$ & $0.12(0.01)$ & $0.23(0.01)$ & $0.95(0.05)$ \\
\hline
\end{tabular}

${ }^{1}$ Quartiles: $1=0-25 \% ; 2=26-50 \% ; 3=51-75 \% ; 4=76-100 \%$.

${ }^{2}$ Standard error of 0.00 is an artifact of the calculation program (VCE 4.0).

traits between the 2 environments were small and did not change the overall result of whether a $\mathrm{G} \times \mathrm{E}$ was present.

Heritabilities, permanent environmental variation, and genetic correlations in Table 12 compared with Table 10 show that reducing heteroscedasticity had little effect on the heritabilities, the permanent environmental variations, or their standard errors. For all traits, the heritabilities and permanent environment effects showed no trend in adjustment after the transformation; in all cases, the changes were negligible. Genetic correlations of MEM and LSCS within quartiles were largely unaffected by adjusting for heteroscedasticity. The first quartiles of protein and fat changed in opposite directions. Although it may be expected that changes in MEP would be more similar to MEM because of a somewhat stronger correlation than for MEF with MEM, the reduced correlation for MEF after transformation was unexpected. It may have resulted from an irregular relationship of variance of MEF, MEP, and MEM within the MEM variance quartiles. In all cases, it was noted that if a $\mathrm{G} \times \mathrm{E}$ or scaling effect did not exist before the transformation, it did not exist after the transformation; however, it was expected that the transformation would remove a scaling effect rather than add one. As expected, the transformation incorporated here may not have completely removed all heteroscedasticity, but our objective was to compare hetero- scedasticity in G vs. C herds using the transformation incorporated by USDA-AIPL in US genetic evaluations.

A $\mathrm{G} \times \mathrm{E}$ was found for the first and second variance quartiles in G herds (Table 10). This would suggest that sires' PTA might not be adequate for $\mathrm{G}$ herds as progeny testing is typically carried out in $\mathrm{C}$ systems. One way to correct for this would be to introduce separate progeny testing for G herds; however, this would not be practical due to the expense (Weigel et al., 1999).

\section{CONCLUSIONS}

The data set was divided into variance quartiles based on the variance of MEM. Means of all data sets were unaffected by the transformation to reduce withinherd phenotypic heteroscedasticity; however, standard deviation ranges were reduced.

Regression coefficients were used to determine the adequacy of sires' PTA in predicting performance of daughters. Levels of phenotypic performance in the lower variance quartiles (mostly the first and second) of G herds were inadequately predicted by the sires' PTA but prediction was satisfactory for the upper quartiles of $\mathrm{G}$ herds and all quartiles for $\mathrm{C}$ herds. This may be because sires for the US dairy industry are progeny tested primarily in $\mathrm{C}$ systems, and their PTA values are a result of this. Graziers using the least intensive management should be advised that bull PTA 
for milk, fat, and protein might not be as predictive of future daughter performance as in $\mathrm{C}$ herds or the more intensively managed G herds. Accounting for heteroscedasticity did not resolve the issue for low-variance G herds.

Heritabilities were largely unaffected in all analyses by the incorporation of a transformation to reduce heteroscedasticity, so current heritability figures for the industry are valid for both $\mathrm{G}$ and $\mathrm{C}$ herds. Genetic correlations were not significantly $<1$ among higher quartiles. However, in lower quartiles there were genetic correlations less than 0.80 , suggesting a biologically significant interaction. The results of these genetic correlations suggest that MEM, MEP, MEF, and LSCS in high-producing $\mathrm{G}$ herds are largely being controlled by the same genes as in $\mathrm{C}$ herds.

\section{ACKNOWLEDGMENTS}

Sincere gratitude is owed to John Clay and Crystal Vierhout at the Dairy Records Management Systems (Raleigh, NC) for providing lactation data. We would like to thank Paul VanRaden and George Wiggans for providing pedigree data. Gratitude is also owed to Francis Kearney and Joy Li for the use of their computer editing programs, which made this task an easier one. The authors appreciate the contributions of 2 anonymous reviewers whose suggestions improved the quality of this paper.

\section{REFERENCES}

Boettcher, P. J., J. Fatehi, and M. M. Schutz. 2003. Genotype $\times$ environment interactions in conventional versus pasture-based dairies in Canada. J. Dairy Sci. 86:383-404.

Boldman, K. G., and A. E. Freeman. 1990. Adjustment for heterogeneity of variances by herd production level in dairy cow and sire evaluation. J. Dairy Sci. 73:503-512.

Calus, M. P. L., A. F. Groen, and G. de Jong. 2002. Genotype $\times$ environment interaction for protein yield in Dutch dairy cattle as quantified by different models. J. Dairy Sci. 85:3115-3123.

de Veer, J. C., and L. D. Van Vleck. 1987. Genetic parameters for first lactation milk yields at three levels of herd production. J. Dairy Sci. 70:1434-1441.

Dette, H., and W. K. Wong. 1999. Optimal designs when the variance is a function of the mean. Biometrics 55:925-929.

Everett, R. W., and J. F. Keown. 1984. Mixed model sire evaluation with dairy cattle - Experience and genetic gain. J. Anim. Sci. 59:529-541.

Hill, W. G. 1984. On selection among groups with heterogeneous variance. Anim. Prod. 39:473-477.

Hill, W. G., M. R. Edwards, M. K. A. Ahmed, and R. Thompson. 1983. Heritability of milk yield and composition at different levels and variability of production. Anim. Prod. 36:59-68.
Jones, L. P., and M. E. Goddard. 1990. Five years experience with the animal model for dairy evaluation in Australia. Proc. 4th World Congr. Genet. Appl. Livest. Prod., Edinburgh, Scotland XIII:382-385.

Kearney, J. F., M. M. Schutz, P. J. Boettcher, and K. A. Weigel. 2004a. Genotype by environment interaction for grazing versus confinement. I. Production traits. J. Dairy Sci. 87:501-509.

Kearney, J. F., M. M. Schutz, P. J. Boettcher, and K. A. Weigel. 2004b. Genotype by environment interaction for grazing versus confinement. II. Health and reproductive traits. J. Dairy Sci. $87: 510-516$

Legates, J. E. 1962. Heritability of fat yields in herds with different production levels. J. Dairy Sci. 45:990-993.

Lofgren, D. L., W. E. Vinson, and R. E. Pearson. 1985. Heritability of milk yield at different herd means and variance for production. J. Dairy Sci. 68:2737-2739.

Meinert, T. R., R. E. Pearson, W. E. Vinson, and B. G. Cassell. 1988. Effect of within-herd variance and herd mean production on response to selection within-herd. J. Dairy Sci. 71:3405-3414.

Mirande, S. L., and L. D. Van Vleck. 1985. Trends in genetic and phenotypic variances for milk production. J. Dairy Sci. 68:2278-2286.

Neumaier, A., and E. Groeneveld. 1998. Restricted maximum likelihood estimation of covariances in sparse linear models. Genet. Sel. Evol. 30:3-26.

Robertson, A., L. K. O'Connor, and J. Edwards. 1960. Progeny testing for bulls at different management levels. Anim. Prod. 2:141-150.

Schutz, M. M., P. M. VanRaden, and G. R. Wiggans. 1994. Genetic variation in lactation means and somatic cell scores for six breeds of dairy cattle. J. Dairy Sci. 77:284-293.

Short, T. H., R. W. Blake, R. L. Quaas, and L. D. Van Vleck. 1990. Heterogeneous within-herd variance. 1. Genetic parameters for first and second lactation milk yields of grade Holstein cows. J. Dairy Sci. 73:3312-3320.

Smothers, C. D., R. E. Pearson, I. Hoeschele, and D. A. Funk. 1993. Herd final score and its relationship to genetic and environmental parameters of conformation traits of United States Holsteins. J. Dairy Sci. 76:1671-1677.

Smothers, C. D., R. E. Pearson, W. E. Vinson, and D. A. Funk. 1991. Relationships among phenotypic standard deviation and herd level for type and their effects on selection response in United States Holsteins. J. Dairy Sci. 74:637-644.

Sullivan, P. G., and L. R. Schaeffer. 1989. Regional heterogeneity of variance and its effect on Candian Holstein sire evaluation. Can. J. Anim. Sci. 69:605-612.

Van der Werf, J. H. J., T. H. E. Meuwissen, and G. de Jong. 1994. Effects of correction for heterogeneity of variance on bias and accuracy of breeding values estimation for Dutch dairy cattle. J. Dairy Sci. 77:3174-3184.

Van Vleck, L. D., and M. C. Dong. 1988. Genetic (co)variances for milk, fat, and protein yield in Holsteins using an animal model. J. Dairy Sci. 71:3040-3046.

Vinson, W. E. 1987. Potential bias in genetic evaluations from difference in variation within-herds. J. Dairy Sci. 70:2450-2455.

Weigel, K. A., T. Kriegl, and A. L. Pohlman. 1999. Genetic analysis of dairy cattle production traits in a management intensive rotational grazing environment. J. Dairy Sci. 82:191-195.

Wiggans, G. R., and P. M. VanRaden. 1991. Method and effect of adjustment for heterogeneous variance. J. Dairy Sci. 74:43504357.

Winkleman, A., and L. R. Schaeffer. 1988. Effect of heterogeneity of variance on dairy sire evaluations. J. Dairy Sci. 71:3033-3039. 